NBER WORKING PAPER SERIES

UNEMPLOYMENT INSURANCE AND UNEMPLOYMENT SPELLS

Bruce D. Meyer

Working Paper No. 2546

\author{
NATIONAL BUREAU OF ECONOMIC RESEARCH \\ 1050 Massachusetts Avenue \\ Cambridge, MA 02138 \\ March 1988
}

I would like to thank Robert Moffitt for providing the data and answering numerous questions. I have benefited from comments by Hank Farber, Jerry Hausman, Larry Katz, Dale Mortensen, Glenn Sueyoshi and seminar participants at Chicago, MIT, Minnesota, Northwestern, and the NBER Labor Studies Group. The Sloan Foundation provided financial support. The research reported here is part of the NBER's research program in Labor Studies. Any opinions expressed are those of the author and not those of the National Bureau of Economic Research. 


\title{
Unemployment Insurance and Unemployment Spells
}

\begin{abstract}
This paper tests the effects of the level and length of unemployment insurance (UI) benefits on unemployment durations. The paper particularly studies individual behavior during the weeks just prior to when benefits lapse. Higher UI benefits are found to have a strong negative effect on the probability of leaving unemployment. However, the probability of leaving unemployment rises dramatically just prior to when benefits lapse. When the length of benefits is extended, the probability of a spell ending is also very high in the week benefits were previously expected to lapse. Individual data are used with accurate information on spell durations, and the level and length of benefits: Semiparametric estimation techniques are used and compared to alternative approaches. The semiparametric approach yields more plausible estimates and provides useful diagnostics.
\end{abstract}

Bruce D. Meyer Northwestern University and NBER 2003 Sheridan Road Evanston, IL 60208 (312) $491-8484$ 


\section{Introduction}

This paper exarines the effects of the level and length of unemployment insurance (UI) benefits on unemployment durations. The paper particularly studies individual behavior during the weeks just prior to when benefits lapse. Higher UI benefits are found to have a strong negative effect on the probability of leaving unemployment. However, the probability of leaving unemployment rises dramatically just prior to when benefits lapse. When the length of benefits is extended, the probability of a spell ending is also very high in the week benefits were previously expected to lapse. Individual data are used with accurate information on spell durations, and the level and length of benefits.. Semiparametric estimation techniques are used and compared to alternative approaches. The semiparametric approach yields more plausible estimates and provides useful diagnostics.

\section{Theory}

Unemployment behavior with finite duration UI has been analyzed in several ways. Mortensen (1977) uses a dynamic search model. In his model, individuals maximize the present value of expected utility, where utility is a function of income and leisure. There is no saving in the model; individuals consume their income. A stationary known wage offer distribution is assumed. and the arrival rate of job offers is constant over time for a given search intensity. Mortensen's escape rate or hazard is proportional to $s[1 \cdot F(w)]$, where $s$ is the search intensity, $w$ is the reservation wage and $F$ is the cumulative distribution of wage offers. The hazard rises with search intensity because the arrival rate of job offers increases. The hazard also rises as the reservation wage declines since the probability of an offer being acceptable rises. $s$ is shown to increase as one gets closer to when benefits 
lapse, while w decreases as exhaustion approaches. ${ }^{1}$ Both derivatives imply that the hazard rises up until the point of UI exhaustion. After exhaustion, the environment facing an unemployed individual does not change implying a constant hazard. The time pattern of the hazard is shown in Figure 1, where I is the length of UI benefits. ${ }^{2}$

Moffitt and Nicholson (1982) use a version of the static labor-leisure model of individual choice. In this model people have preferences over two goods, income and unemployment. Unemployment has utility because of its leisure value and because one can search. The new job wage is fixed and a job can be found at any time. At the time of job loss, an individual chooses income and weeks of unemployment subject to a budget constraint. The budget constraint has a convex kink at the week of benefit exhaustion because unemployment ceases to be subsidized. Figure 2 shows the budget constraint. $W$ is the wage, $R$ is the fraction of the wage replaced by $U I$ benefits and $T$ is the length of benefits. An indifference curve through the kink point can have an implied marginal rate of substitution equal to any value between the slopes of the two budget constraint segments. Thus, many people will maximize their utility by returning to work the week benefits lapse. Moffitt and Nicholson

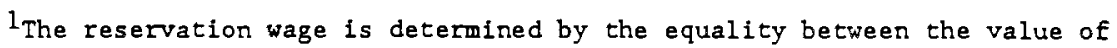
being employed at one's reservation wage and being unemployed (equation 9(a) in Mortensen (1977)). The reservation wage must decline as exhaustion approaches since the value of being unemployed drops. Search intensity is determined by the equality of the marginal cost of search (lost leisure) and the marginal benefit of search (equation $9(b)$ in Mortensen (1977)). Since the marginal benefit of search increases when the value of unemployment declines, search intensity increases.

2 The figure is drawn assuming the marginal utility of leisure is independent of income. If leisure and income are complements (substitutes), the hazard is discontinuous at $T$ and higher (lower) after $T$ than shown. 
then argue informally that the random nature of job finding will cause a clustering of observations around the exhaustion point.

The two models make very different assumptions but have similar predictions. In the Mortensen model the individual is uncertain when a job will be found and what the wage will be. One remains unemployed until a sufficiently high paying job is found: In the Moffitt and Nicholson model one can find a job at a fixed wage anytime. The model emphasizes the leisure value that a period of not working may have if one optimizes over a long period of time such as a year. This explanation makes more sense if there is a significant demand for home production or it is difficult to take a vacation once a new job has begun. ${ }^{3}$ Both models simflarly predict a rising hazard as the UI exhaustion point approaches. Because of the stationarity assumptions, Mortensen's model implies a monotonic increase in the hazard as exhaustion approaches. The Moffitt and Nicholson model is less precise but a rise in the hazard around the exhaustion point is implied.

There are several aspects of UI unemployment spells that are not captured by these models. The length of UI benefits often changes in the course of an unemployment spell. In the sample studied below about 47 percent of UI recipients experienced a change in their length of benefits. Second, individuals may make arrangements to return to a job several weeks before they actually do. Third, recall is quantitatively more important than new job finding for most UI recepients. Using data from two states, Corson and Nicholson (1984) and Katz and Meyer (1987) find that about 60 percent of spells end in recall. Katz (1985) provides a clear discussion of search with

${ }^{3}$ Implicit in this discussion is the assumption that the search requirement for UI receipt can be satisfied at low cost. 
recall and infinite length unemployment insurance. However, recall dates likely depend on individual or typical VI benefit lengths. If workers are bound to firms by implicit contraces, moving costs, specific human capital, or other reasons, firms have an incentive to base recall decisions on the length of UI benefits.

Mortensen (1987) provides a model which has this characteristic. He analyzes a joint wealth maximizing model of job separations with firms facing transitory demand changes and limited duration of unemployment benefits. The discrete change in the flow value of being unemployed when benefits are exhausted yields the prediction that many firms may recall laid-off workers around the benefit exhaustion point.

\section{Data}

The data are from the Continuous Wage and Benefit History (CWBH) UI administrative records used by Moffitt (1985a, 1985b). Males from twelve states during the period 1978-1983 are examined. The advantage of CWBH data is accurate information on weeks of UI receipt, pre-unemployment earnings, the UI benefit, and the potential duration of benefits over time. The importance of accurate data is highlighted by the large degree of measurement error that has been found in the weeks unemployed variable in some household surveys. ${ }^{4}$

${ }^{4}$ Poterba and Summers (1984) and Sider(1984) examine the Current Population Survey. Using data matched across two consecutive months, Poterba and Summers check if the reported length of continuing unemployment spells increases by four to five weeks in the course of a month. Allowing for a three-week margin of error they find that only 57 percent of responses are consistent. Sider studies the distribution of reported incomplete unemployment spells. He finds a pronounced tendency to report round numbers such as 26 and 39 weeks. This clustering cannot be due to UI since these are incomplete spell lengths. 
Additionally, the UI parameters, benefit level and duration, are often missing from other data sources. The CWBH data provide accurate information on these key variables.

The disadvantage of the data is that only information on weeks compensated by the UI system is available. Individuals are censored when their benefits lapse, so behavior beyond the exhaustion point cannot be examined. Also, an individual may not receive UI continuously; weeks may be skipped during which benefits are not received. 5 The spell of benefit receipt may be more useful than the unemployment spell when unemployment is briefly interrupted but followed by more unemployment. The spell of benefit receipt may do a better job of grouping together periods of similar behavior. The sample is composed of two parts of roughly equal size. The first part is a random sample, while the second oversamples from states and time periods that are more likely to have unchanging benefit lengths.

The Moffitt dataset contains 4,628 observations. Two exclusions ${ }^{6}$ leave 3,365 observations which are analyzed. Descriptive statistics for the sample are given in Table 1. The mean pre-UI weekly income is 169.5 after taxes (in 1977 dollars). The mean weekly benefit is 104.2 .70 is the mean UI replacement ratio (benefits divided by after-tax income). The mean beginning

${ }^{5}$ The sample is restricted to those whose gaps between periods of benefit receipt are cumulatively less than ten weeks. See Moffitt (1985a, 1985b) for a more detailed discussion.

61,227 observations have missing data on age, schooling, dependents or marital status. 36 observations have negative values for time until benefits lapse.

7 The marginal tax rate was calculated by walter Corson of Mathematica Policy Research. The calculations use family income and account for state and federal income taxes and Social Security payroll taxes 
of spell state unemployment rate is fairly high during this period at 8.7 percent. The average number of weeks of benefits received is just over 13 .

A more complete illustration of the pattern of weeks of UI receipt and censoring can be seen in Table 2 and Figure 3. Table 2 gives the empirical hazard for the data. The empirical hazard is the fraction of spells ongoing at the start of a week which end during the week. ${ }^{8}$ In Figure 3 there are several periods when the empirical hazard is noticeably higher than surrounding periods. The high hazard in the first several weeks is probably caused by the high frequency of recalls in the early weeks of unemployment. ${ }^{9}$ The hazard is higher between 25 and 29 weeks and then again between 35 and 38 weeks. These jumps are probably caused by UI exhaustion. An examination of Table 3 provides some evidence on this point. Table 3 reports the distribution of two measures of the length of UI benefits. Initial length is the number of weeks of benefits an individual is entitled to when his spell begins. Since benefit lengths often change in the course of an individual's spell, the maximum length is also reported. The rises in the hazard are roughly coincident with weeks when benefits commonly lapse. However the timing of some of the peaks in the hazard is inconsistent with the earlier theories. The peak at 26 for example, cannot be caused by benefits running out after 26 weeks. Such individuals would be censored at 26 so we would not observe the end of their spells. This is discussed in more detail later.

${ }^{8}$ More formally, the empirical hazard for week $t\left(H_{t}\right)$, is the number of failures during the week $\left(D_{t}\right)$, divided by the size of the risk set at the beginning of the week. The size of the risk set at the beginning of week $t$ $\left(R_{t}\right)$, is just the number of people whose spells have not ended or been censored at the beginning of week $t$. Algebraically, $H_{t}-D_{t} / R_{t} . C_{t}$ is the number of observations which are censored at the beginning of week $t . C_{t}=$ $R_{t-1}-D_{t-1}-R_{t}$.

${ }^{9}$ See Corson and Nicholson (1983) and Katz (1985, 1986). 
There are several causes for the varlability in benefit lengths seen in Table 3. First, there is varlabllity across states in the length of regular benefits provided. During the sample period, Loulsiana typically provided 28 weeks, Pennsylvania provided 30 weeks, whlle most other states provided 26 weeks of benefits. Second, benefits were extended during periods of high unemployment under several federal programs. The Extended Benefits program extended benefits 50 percent beyond state durations, up to a maximum of 39 weeks, whenever the insured unemployment rate was above a trigger level ... In 1981, the system changed from a state or federal trigger to a higher, state only trigger. Two other programs provided supplemental benefits. At the beginning of the sample perlod, the Federal Supplemental Benefits progran provided up to a total of 65 weeks of benefits. Beginning in the Fall of 1982 the Federal Supplementary Compensation program frovided up to 62 weeks of benefits. These first two sources of variation are quantitatively the most important. Lastly, within a state at a point in time the length of benefits may depend on an individual's work history. The distribution of benefit lengths reported in Table 3 reflects all of these factors.

I initially examine the effects of finite length UI benefits nonparametrically and without explanatory variables. Table 4 gives an empirical hazard analogous to the Kaplan-Meier estimator. Figure 4 displays a graph of the hazard. The time axis is time until benefits lapse rather than time since a spell began. There is a noticable rise in the hazard about five weeks before benefits lapse. The hazard also jumps dramatically the week before benefits end. For the other weeks there is no discernable trend, except a somewhat lower hazard when exhaustion is more than nine months away. 


\section{Duration Models}

Several aspects of Table 4 point to the need for more sophisticated modeling. The hazard is high at $24,25,36,37$, and 38 weeks before exhaustion. This is due to the large number of people with initial durations of 26 and 39 weeks, and the higher baseline hazard in the first few weeks of unemployment as seen In Figure 3. Additionally, the Kaplan-Meier hazard assumes that the sample is homogeneous, i.e., that there is no heterogeneity which depends on either observable or unobservable factors. However, one expects that the characteristics causing a lower hazard will be more concentrated among the remaining individuals as one approaches exhaustion. For example, the remaining observations are likely to be disproportionately high benefit, nonwhite, and older. This sorting effect may mask a much larger increase in the hazard as exhaustion approaches. These problems are potentially solved by using a duration model. If the effect of time since the beginning of a spell is handled in a flexible manner it should account for the higher hazard just after 26 and 39 weeks until exhaustion. Similarly, one can look at the pure effect of getting closer to exhaustion, holding other explanatory variables constant.

The importance of time dependent covariates and censoring in the data make a duration model especially useful. The theories of unemployment behavior with UI discussed earlier, imply that the hazard should increase as exhaustion approaches. It is difficult to allow for this with explanatory variables constant over time. The initial duration of benefits does not reflect future extensions. The maximum duration of benefits is an endogenous variable since benefits have a higher probability of being extended if an 
unemployment spell lasts longer. 10 This suggests using a (not necessarily linear) function of time until exhaustion to account for the length of benefits. Regression approaches to this problem are further plagued by the censoring of over a quarter of the spells. The biases from censoring are discussed extensively by Welch (1977) in the context of UI studies.

Greene(1981) and Chung and Goldberger(1984) derive the magnitude of the bias under certain assumptions. Alternatively, one can assume a shape for the distribution of spells and use Tobit type techniques, but estimates are very sensitive to the assumed shape. 11 A duration model can be less parametric about the shape of the distribution and still allow censoring.

The estimation approach used here is an extension of Prentice and Gloeckler (1978) which is discussed extensively in Meyer (1986). The shape of the hazard is nonparametrically estimated. In this respect the approach is similar to the method used successfully by Moffitt (1985a). 12 However, the approach taken here has several advantages. The estimates are parameters of a continuous time hazard model and thus retain an easy interpretation... Second, the probabilites of surviving each period are constrained to lie between 0 and 1. Third, there is a large literature discussing the importance of allowing

${ }^{10}$ Consider the case where the initial length of benefits is the same for al1 individuals and assume that the length of benefits does not affect the length of spells. If benefits have a positive probability of being extended each period, the expected value of the maximum duration will be a monotonic function of the dependent variable.

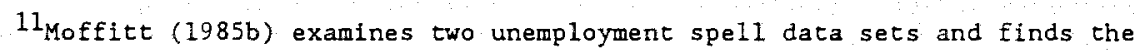
estimates to be quite sensitive to the distribution assumed. An alternative approach which would eliminate the distributional assumption would involve slightly modifying semiparametric estimators for Tobit models such as Powell (1984).

12 Green and Shoven (1986) use an approach close to Moffitt's in their examination of mortgage prepayments. 
for unobservable differences across people. ${ }^{13}$ These differences are usually called unobserved heterogeneity. It is relatively easy to test for heterogeneity and estimate it parametrically in this model. The distribution of the heterogeneity component can be nonparametrically estimated as well. Formally, let $T_{i}$ be the length of individual i's unemployment spell. Then the hazard for individual $i$ at time $t, \lambda_{i}(t)$. Is defined by the equation

$$
\lim _{h \rightarrow 0^{+}} \frac{\operatorname{prob}\left[t+h>I_{i} \geq t \mid I_{i} \geq t\right]}{h}-\lambda_{i}(t) \text {. }
$$

The hazard is parameterized here using the proportional hazards form, i.e.

$$
\lambda_{i}(t)=\lambda_{0}(t) \exp \left\{z_{i}(t) \cdot \beta\right\},
$$

where

$\lambda_{0}(t)$ is the baseline hazard at time $t$, which is unknown,

$z_{i}(t)$ is a vector of time dependent explanatory variables for individual $i$, and

$\beta$ is a vector of parameters which is unknown.

The probability that a spell lasts until time $t+1$ given that it has lasted until $t$ is easily written as a function of the hazard.

$$
\begin{aligned}
P\left[T_{i} \geq t+I \mid T_{i} \geq t\right] & =\exp \left[-\int_{t}^{t+1} \lambda_{i}(u) d u\right] \\
& =\exp \left[-\exp \left(z_{i}(t)^{\prime} \beta\right) \cdot \int_{t}^{t+1} \lambda_{0}(u) d u\right]
\end{aligned}
$$

given that $z_{i}(t)$ is constant between $t$ and $t+1$.

Equation (1) can be rewritten as

$$
P\left[T_{i} \geq t+1 \mid T_{i} \geq t\right]=\exp \left[-\exp \left(z_{i}(t)^{\prime} \beta+\gamma(t)\right)\right]
$$

where

13 Examples include Lancaster (1979) and Heckman and Singer (1984). 
(3)

$$
\gamma(t)=\ln \left(\int_{t}^{t+1} \lambda_{0}(u) d u\right)
$$

The log-likelihood for a sample of $N$ individuals can be written as a function of terms such as (2). 14

(4) $L(\gamma, \beta)-\sum_{i-1}^{N}\left[\delta_{i} \log \left[1-\exp \left\{-\exp \left[\gamma\left(k_{i}\right)+z_{i}\left(k_{i}\right)\right)^{\prime} \beta\right]-\sum_{t-1}^{k_{i} l} \exp \left[\gamma(\tau)+z_{i}(t) \cdot \beta\right]\right]\right.$

where $C_{i}$ is the censoring time, $\delta_{i}-1$ if $T_{i} \leq C_{i}$ and 0 otherwise, and $k_{i}=$ min(int $\left.\left(T_{i}\right), C_{i}\right)$. It is assumed that censoring does not provide any information about $T_{i}$ beyond that available in the covariates.

Observations lasting more than 39 weeks were censored at 39 , only 2.4 percent of the spells were continuing at this point. Given the small number of observations lasting more than 39 weeks; one would need to make strong parametric assumptions to make inferences about very long unemployment spells. The likelihood function (4) is now a function of $\beta$ and the 38 elements of $\gamma$. The likelihood is easily maximized by standard techniques. If unobserved heterogeneity is present the hazard becomes

$$
\lambda_{i}(t)-\theta{ }_{i} \lambda_{0}(t) \exp \left\{z_{i}(t)^{\prime} \beta\right\}
$$

where $\theta_{i}$ is a random variable that is assumed to be independent of $z_{i}(t)$.

This model can be estimated given a parametric assumption on the distribution of $\theta_{i}$. Even if the distribution of $\theta_{i}$ is unknown, $\gamma$ and $\beta$ can be consistently estimated using an extension of the Heckman and Singer (1984) approach. See Meyer (1986) for the likelihood function and a proof of consistency.

${ }^{14}$ See equation (2.6) and the surrounding text in Meyer (1986) for a complete description. 


\section{Results}

The effects of unemployment insurance are measured using functions of the benefit level and the time until benefits lapse. The log of weekly benefits and pre-UI income are included in most specifications. Similar results are obtained when the level of benefits and income are used and when the UI replacement ratio is tried. High benefits are expected to decrease the hazard because they lower the opportunity cost of search and leisure. High previous earnings are expected to raise the hazard since the cost of unemployment in terms of lost wages is higher and because high earnings are likely correlated with unobserved job finding ability. The other UI variables are UI 1 to UI 4l-54 which form a spline in time until benefit exhaustion. The coefficient on UI 2.5 is the additional effect on the hazard of having moved 1 week closer to exhaustion when one is $2-5$ weeks away. The coefficient on UI 1 is the additional effect on the hazard when one moves from 2 to 1 week from exhaustion. Thus, the effect of moving from 6 weeks away to 1 week is 4 times the UI $2-5$ coefficient plus the UI 1 coefficient. The other UI coefficients have analogous interpretations.

Formally, let $r$ be the number of weeks until benefits lapse. Then UI $1-1$ if $r=1$, and 0 otherwise

UI $2-5=\min (6-\tau, 4)$ if $\tau \leq 5$, and 0 otherwise

UI $6 \cdot 10=\min (11-\tau, 5)$ if $\tau \leq 10$, and 0 otherwise, and similarly for the remaining variables.

The theories discussed in section 2 predict that the exhaustion spline coefficients should be positive. The prediction depends on the stationarity 
of the offer arrival function and the wage distribution in Mortensen (1977). If the stationarity assumptions are relaxed, the predictions of the model are indeterminant. However, one might well find that the exhaustion effect dominates in the weeks just before exhaustion, implying positive coefficients for these spline segments.: In Moffitt and Nicholson (1982) the prediction for the segments far from exhaustion depends on the distribution of preferences. Thus, the most robust prediction seems to be positive coefficients on the segments close to exhaustion.

The results are reported in Tables 5 through 9 . The coefficients on the explanatory variables are in Tables 5 and 6 . The simpler specifications are discussed first, then the more sophisticated ones... The weekly benefit and after-tax weekly earnings coefficients have the expected signs and are precisely estimated. High wages and low benefits increase the hazard. Using the coefficient estimates from specification (1), which are typical, a 10 percent increase in benefits at the mean is associated with an 8.8 percent decrease in the hazard. The time until exhaustion spline coefficients are jointly highly significant, two of the coefficients are significant individually. The point estimates indicate that moving from 54 to 41 weeks from exhaustion increases the hazard by 32 percent. Between 41 to 6 weeks the hazard is basically flat, but the point estimate is a small decrease in the hazard. From 6 to 2 weeks until exhaustion the hazard rises 67 percent, and 1 week away the hazard rises an additional 97 percent. Cumulatively, the hazard more than triples as one moves from 6 weeks to 1 week until exhaustion.

The coefficient on the state unemployment rate has the expected sign and is significantly different from zero. In specification (1), the implied effect of a one percentage point increase in the unemployment rate is a 2.4 
percent reduction in the hazard. The hazard falls almost monotonically with age. Those 17-24 have the highest hazard while those 55 and over have the lowest.

Table 7 illustrates the value of the baseline hazard parameters as a diagnostic tool. Even with the time until exhaustion spline included in the specification, spikes in the hazard remain at $26,28,32$, and 36 weeks. The spikes may be caused by individuals arranging to be recalled or begin a new job well before benefits run out. If benefits are extended in the intervening period, the result would be a higher hazard after common UI exhaustion points.

This hypothesis is tested by adding a variable equal to 1 in week $t$, if earlier in the spell it was expected that benefits would lapse at $t .15$ The yariable is used in specification (3) and specifications (5) through ( 8 ). The coefficient always has a large asymptotic t-statistic. The point estimates imply a four- to five-fold increase in the hazard in the week benefits were expected to lapse. When the benefits expected to lapse variable is included, the spikes at 26,28 , and 36 are no longer present, and the one at 32 declines. This result can be seen by comparing Table 7 with Table 8 and Table 9. The estimates provide support for the hypothesis that early in spells some firms and employees plan when unemployment will end. 16 This finding accords with the Moffitt and Nicholson model in which the length of the unemployment spell is selected when unemployment begins. An alternative explanation for

${ }^{15}$ It is assumed that changes in UI benefit lengths are not foreseen. To predict changes, an individual would need to predict unemployment rates and congressional actions. As long as the prediction is not perfect, one would expect an effect of the old exhaustion date on the hazard.

${ }^{16}$ I originally included separate variables for recent changes in the length of benefits (in the last 8 weeks) and changes that took place anytime during the spell. The coefficient on the within the last 8 weeks variable was always larger but never significantly different from the other coefficient. 
the result might be that some people eligible for extended benefits do not claim them, despite the simplicity of the procedure and the financial reward.

The second advantage of nomparametric estimation of the baseline hazard is consistency of covariate coefficients when the shape of the baseline hazard is not known. Despite lack of theoretical support for any particular shape, numerous authors have fitted models with a Weibull baseline hazard.

Specifications (2) and (6) impose a Weibull baseline, allowing a comparison of techniques. Likelihood ratio tests of the null hypothesis of a Weibull baseline reject, Indicating that the Weibull model is misspecified. The chi-square statistics with 36 degrees of freedom are 93.98 and 58.32 for specifications (2) and (6), respectively. 17 Note that the Weibull assumption is a much better approximation when the benefits expected to lapse variable is included.

There is some evidence that the Weibull assumption has biased the coefficients, particularly those on the time-varying covariates... In specification (1) the unemployment rate coefficient is negative and significant, while in the Weibull model of specification (2) it is positive. Two of the coefficients of the UI exhaustion spline also change sign, but they are insignificant using either estimator.. The coefficients on time-constant covariates are very close in the two sets of estimates. These results confirm intuitive arguments about the effects of misspecifying the baseline hazard. Since the time pattern of the hazard has been misspecified, coefficients on time-varying covariates, which depend on the time pattern of the hazard, are

${ }^{17}$ The critical values at the .05 and .01 level are 51.00 and 58.62 , respectively. Specification (2) is rejected at conventional significance levels. Specification (5) is rejected at the .05 level, but just passes at the .01 level. 
more likely to be blased than other coefficients. This result has also been found in some preliminary Monte Carlo experiments.

Specifications (4) through (9) include state fixed effects. Fixed effects are included because omitted state characteristics may affect both unemployment and the generosity of state UI systems. The omission of fixed effects in this situation would bias estimated UI responses. 18 Several authors have found variables which are correlated with both unemployment and the generosity of UI programs. Medoff (1979) finds that the layoff subsidy from incomplete UI experience rating is higher for union establishments than nonunion establishments. Unionization also leads to greater use of layoffs independent of the UI subsidy. Adams (1986) finds that the UI subsidy per worker to employers is correlated with the diversifiability of state employment, the skewness of state unemployment rates, and several industrial characteristics. However, it is unclear whether the correlations found by Medoff and Adams reflect the political economy of UI legislation or the effects of UI on employment and layoff patterns. 19

A comparison of specifications (3) and (7) overwhelmingly supports the presence of state fixed effects. The likelihood ratio test statistic is 217.78 and is distributed chi-square with 11 degrees of freedom under the null hypothesis of no fixed effects. 20 There is some evidence that the endogeneity

${ }^{18}$ The omitted state characteristics are assumed to be constant over the sample period so that fixed effects estimates are consistent.

${ }^{19}$ The latter view is adopted by Deere and Miron (1986) who argue that the distribution of state employment by industry is shaped by UI laws.

${ }^{20}$ The critical values at the .05 and .01 level are 19.68 and 24.72 , respectively. The states with the lowest hazards all else equal are Nevada, New Mexico, and Wisconsin. Missouri, North Carolina, and South Carolina have the highest hazards. 
of state UI laws biases the UI benefit coefficient in the estimates without fixed effects. Specifications (3) and (7) are identical except for the use of fixed effects in (7). In the flxed effects specification the coefficient on benefits drops 29 percent in absolute value to -60 . All other fixed effects specifications have similar coefficients in the -.50 to -.60 range, except specifications (4) and (5). The coefficlents in specifications (4) and (5) have a slightly different interpretation because of the large unobserved heterogeneity variance. The inclusion of unobserved heterogeneity tends to increase the absolute value of coefficients, even though expected duration elasticities may not change much. 21 The exhaustion spline and benefits expected to lapse variables do not appreciably change.

The introduction of state fixed effects dramatically changes the state unemployment rate coefficient. The unemployment rate is the monthly CPS state unemployment rate interpolated to give a weekly series. In the specifications with a nonparametric baseline but without state flxed effects (specifications (1) and (3)), the coefficient on unemployment is negative. These specifications estimate the unemployment coefficient using variation in unemployment across states as well as over time.. On the other hand, state fixed effects specifications control for the state level of unemployment and

${ }^{21}$ The coefficients reported are always the logarithmic derivatives of the hazard with respect to the covariates. Even when these logarithmic derivatives are the same, elasticities of other measures of spell length may change. This rescaling effect is discussed in Lancaster (1979, 1985). In a hazard model with no time-varying regressors, no censoring, and a weibuli baseline hazard, Lancaster (1985) derives the asymptotic bias from omission of heterogeneity. He finds that all coefficients are biased towards zero by the same proportion: However, elasticities with respect to the expected value of the $\log$ of duration are unbiased. With censored data and time-varying covariates the appropriate elasticity to report is unclear. A good approach might be to report the elasticities of the probability of a spell lasting a given number of weeks, for a representative path of the covariates. 
only use the time-series variation in unemployment to estimate the coefficient. In the six specifications with state fixed effects (specifications (4) through (9)), the state unemployment rate coefficient is positive and almost always significantly different from zero.

These results imply that across state and over time variation in unemployment have opposite effects for this time period. States with higher unemployment rates, all else equal, have longer unemployment spells, However, a rise in the unemployment rate over time for a given state is associated with a shortening of unemployment spelis in that state. An explanation for this result is that layoffs are countercyclical; in recessions the fraction of unemployment due to layoffs rises. 22 Layoff spells also tend to be shorter. Thus, it would not be surprising if the average duration of unemployment spelis fell. As mentioned earlier, layoff spells are particularly concentrated among UI recipients. Furthermore, Dynarski and Sheffrin (1987) find similar results for a sample of household heads during 1980.81 from the PSID. They find that the aggregate U.S. unemployment rate is negatively correlated with unemployment duration, with and without controls for demographic characteristics, industry and occupation. Because the aggregate unemployment rate is used, Dynarski and Sheffrin have analyzed the effects of time-series variation in the unemployment rate. Thus, their estimates accord with the coefficients from the sample studied here.

Allowing for unobserved heterogenelty does not change the conclusions about the effects of UI. Three specifications $(4),(5)$ and (8)), include gamma distributed unobserved heterogeneity. The coefficients on UI benefits, the time until exhaustion spine, and the variable for benefits previously

${ }^{22}$ see Feldstein (1975) and Lilien (1980). 
expected to lapse, are similar in the heterogeneity and no heterogeneity specifications. The UI variables always show strong effects in the directions found earlier. In two specifications, (4) and (5), the variance of the heterogeneity is significantly different from zero. 23 In several other specifications no heterogeneity is found. This result is puzzling, however in Monte Carlo experiments Ridder and Verbakel (1983) find that a zero estimated variance is not uncommon. They find this result even when the estimated and true models are identical. I have also found this result in some preliminary Monte Carlo experiments.

Specifications (5) and (7) allow a direct comparison of estimates with and without heterogeneity. The coefficients in the heterogeneity specification tend to be larger in absolute value as suggested by Lancaster, but among the UI coefficients only the benefit coefficient is appreciably larger. The spline in time until benefit exhaustion, and the benefits expected to lapse variable, are barely affected. The estimated baseline hazard becomes decidedly upward sloping however, when gamma heterogeneity is allowed. Compare Tables 8 and 9 to see this result.

Separate specifications analogous to (8) were estimated for the two subsamples discussed in Section 3. The estimates for the random sample are shown in specification (8). The estimates for the sample with mostly constant benefit lengths are shown in specification (9). In the randorn subsample, benefits have a smaller effect than in specification (5), but similar to specifications (6), (7) and (9). The effect of approaching the week benefits lapse is more pronounced, but the benefits expected to lapse effect is

${ }^{23}$ The asymptotic t-statistics for specifications (4) and (5) are 3.89 and 4.05, respectively. The critical values in a one-taled test at the .05 and .01 levels are 1.64 and 2.33 , respectively. 
slightly smaller. The constant benefit length subsample also gives estimates similar to earlfer ones, except the tine until exhaustion spline is U-shaped as in Moffitt (1985).

\section{Some Comments on the Results and Conclusions}

In the preceeding pages, all of the simpler specifications are rejected in favor of specification (5). For this reason, estimates from specification (5) are used to sumarize the results. The coefficient on the UI benefit level is precisely estimated and implies that a 10 percent increase in benefits is associated with an 8.8 percent decrease in the hazard. The coefficient suggests a relatively large disincentive effect of UI. Somewhat smaller estimates are obtained when the same model is used on the random subsample in specification (8). The benefit coefficient implies that a 10 percent increase in benefits is associated with a 5.3 percent decrease in the hazard. Since specification (5) has a much larger heterogeneity variance, the two specifications may lead to similar expected duration elasticities. One should note that the estimates only apply to the hazard prior to exhaustion. Higher benefits may lead to a higher hazard after exhaustion as suggested by Mortensen (1977).

The time until exhaustion spline coefficients are jointly highly significant; three of the coefficients are individually significanty different from zero an conventional levels. The point estimates imply that moving from 54 to 41 weeks until exhaustion raises the hazard by 46 percent. The hazard is essentially flat between 41 and 6 weeks, but the point estimates imply a small decrease in the hazard. Between 6 and 2 weeks before benefit exhaustion the hazard rises 109 percent. One week away the hazard rises an additional 95 percent. Cumulatively, the hazard more than quadruples as one 
moves from 6 weeks to 1 week until exhaustion. The pronounced rise in the hazard as exhaustion approaches supports the models of both Mortensen (1977) and Moffitt and Nicholson (1982).

While the spike in the hazard just before exhaustion is striking, few spells last sufficiently long to be affected by the spike. Almost all of the effect of UI on mean spell lengths comes from the level of benefits. Here the estimated effect of the benefit level is toward the high end of the distribution of recent estimates. A consensus of the previous estimates of the effect of a ten percentage point increase in the replacement ratio might be a one-half to one week increase in the length of spells. 24 Here the estimate is around one and one-half weeks. The results also differ from those of Topel (1983, 1984) who argues that the key mechanism by which UI raises the unemployment rate is the increased incidence of temporary layoffs rather than the lowered exit rate from unemployment.

Larger estimated effects are a plausible result of better data on spell length and the level and length of benefits. In the CPS data used by Topel, one must make an educated guess whether or not an individual is receiving benefits and then impute their level. Difficulties with the CPS length of unemployment spel1 variable were mentioned in Section 3. However, the estimates are sufficiently different from most other estimates that a further

24 Hamermesh (1977) concludes that "the best estimate-if one chooses a single figure--is that a 10 -percentage point increase in the gross replacement rate leads to an increase in the duration of insured unemployment of about half a week when labor markets are tight." Danziger, Haveman and Plotnick (1981) report a wide range of estimates, but suggest that Moffict and Nicholson (1982) offers the most reliable estimates. Their study found that a 10-percentage point increase in the replacement rate was associated with about a one week increase in the average length of unemployment spells. The estimates in Solon (1985) imply between a half a week and a full week increase in mean durations from a 10 -percentage point increase in the replacement rate. 
examination seems warranted. The sources of variation in benefit levels in the 12 state CWBH data are nonlinearities in the benefit schedules (especially different minima and maxime across states), legislative changes during the sample period, and the erosion of real benefit levels due to inflation between legislative changes. Dfferences in the average benefit generosity across states is absorbed by the state fixed effects in the specifications, and pre-UI weekly earnings are included as an explanatory variable.

Within a given state at a point in time, the benefit level is usualy a simple nonlinear function of previous earnings. Thus, it has been argued, most notably in Welch (1977), that effects of the benefit level on unemployment cannot be separated from the effects of previous earnings. While I believe it is extreme to apply this criticism to the data set used here, as a check on these estimates I plan to examine unemployment spelis in the months around changes in state UI laws. 
Adams, J. (1986): "Equilibrium Taxation and Experience Rating in a Federa1 System of Unemployment Insurance," Journal of Public Economics, 29, $51-77$.

Corson, Walter and Walter Nicholson (1983): "An Analysis of UI Recipients" Unemployment Spells," Unemployment Insurance Occasional Paper 83-1, U.S. Department of Labor, Employment and Training Administration.

Danziger, Sheldon, Robert Haveman, and Robert Plotnick (1981): "How Income Transfer Programs Affect Work, Savings, and the Income Distribution: A Critical Review," Journal of Economic Literature, XIX, 975-1028.

Deere, Donald, and Jeffrey Miron (1986): "The Cross Sectional Impact of Unemployment Insurance on Layoffs, Employment, and Wages," unpublished.

Dynarski, Mark and Steven Sheffrin (1987): "New Evidence on the Cyclical Behavior of Unemployment Durations," in Unemployment and the Structure of Labor Markets, ed. by $\mathrm{K}$. Lang and J. Leonard. London: Basil Blackwell.

Feldstein, Martin (1975): "The Importance of Temporary Layoffs: An Empirical Analysis," Brookings Papers on Economic Activity, 725-744.

Green, Jerry and John Shoven (1986): "The Effects of Interest Rates on Mortgage Prepayments," Journal of Money, Credit, and Banking, $18,41-59$.

Ham, John C., and Samuel A. Rea, Jr. (1987): "Unemployment Insurance and Male Unemployment Duration in Canada," Journal of Labor Economics, 5 , 325-353.

Hamermesh, Daniel S. (1977): Jobless Pay and the Economy. Baltimore: The Johns Hopkins University Press.

Heckman, James and Burton Singer (1984): "A Method for Minimizing the Distributional Assumptions in Econometric Models for Duration Data," Econometrica, 52, 271-320.

Kalbfleisch, John, and Ross Prentice (1980): Statistical Analysis of Failure Time Data. New York: Wiley.

Katz, Lawrence F. (1985): "Worker Mobility and Unemployment," Ph.D. Dissertation, MIT.

Katz, Lawrence F. (1986): "Layoffs, Recall and the Duration of Unemployment,". NBER Working Paper No, 1825.

Katz, Lawrence $F^{\prime}$, and Bruce D. Meyer (1987): "Unemployment Insurance, Recall Expectations and Unemployment Outcomes," unpublished.

Lancaster, Tony (1979): "Econometric Methods for the Duration of Unemployment," Econometrica, 47, 939-956. 
Lancaster, Tony (1985): "Generalised Residuals and Heterogeneous Duration Models with Applications to the Weibuli Model, "Journal of Econometrics, $28,155-169$.

Lilien, David (1980): "The Cyclical Importance of Temporary Layoffs," The Review of Economics and Statistics, 62, 24-31.

Medoff, James (1979): "Layoffs and Alternatives under Trade Unions in U.S. Manufacturing," The American Economic Review, 69, 380-395.

Meyer, Bruce D. (1986): "Semiparametric Estimation of Hazard Models," Mimeo, MIT.

Mortensen, Dale T. (1977): "Unemployment Insurance and Job Search Decisions," Industrial and Labor Relations Review, 30, 505-517.

Mortensen, Dale I. (1987): "A Structiral Model of UI Benefit Effects on the Incidence and Duration of Unemploynent," Mimeo, Northwestern University.

Moffitt, Robert (1985a): "Unemployment Insurance and the Distribution of Unemployment Spelis," Journal of Econometrics, 28,85-101.

Moffitt, Robert (1985b): "The Effect of the Duration of Unemployment Benefits on Work Incentives: An Analysis of Four Data Sets," Unemployment

Insurance Occasional Paper 85-4, U.S. Department of Labor. Employment and Training Administration.

Moffit, Robert, and Walter Nicholson (1982): "The Effect of Unemployment Insurance on Unemployment: The Case of Federal Supplemental Benefits,"The Review of Economics and Statistics, 64, 1-11.

Poterba, James and Lawrence Sumers (1984): "Survey Response Variation in the Current Population Survey, "Monthly Labor Review, 107, 31-37.

Powe11, James I. (1984): "Least Absolute Deviations Estimation for the Censored Regression Model," Journal of Econometrics, 25, 303-325.

Prentice, Ross and Z. Gloeckler (1978): "Regression Analysis of Grouped Survival Data with Application to Breast Cancer Data," Biometrics, 34, 57-67.

Ridder, Geert, and Wim Verbakel (1983): "On the Estimation of the Proportional hazard Model in the Presence of Unobserved Heterogeneity," mimeo, University of Amsterdam.

Sider, Hal (1985): "Unemployment Duration and Incidence: 1968-82," American Economic Review, 75, 465-472.

Solon, Gary (1985): "Work Incentive Effects of Taxing Unemployment Benefits," Econometrica, 53, 295-306. 
Topel, Robert H. (1983): "On Layoffs and Unemployment Insurance," The American Economic Review, 73, 541-559.

Topel, Robert H. (1984): "Equilibrium Earnings, Turnover, and Unemployment: New Evidence," Journal of Labor Economics, 2, 500-522.

Welch, Finis (1977): "What Have We Learned from Empirical studies of Unemployment Insurance?," Industrial and Labor Relations Review, 30 , 451-461. 
Table 1

Descriptive Statistics ${ }^{a}$

\begin{tabular}{lrrrr}
\hline Variable & Minimum & Maximum & $\begin{array}{c}\text { Mean } \\
\text { Age }\end{array}$ & \multicolumn{1}{c}{$\begin{array}{c}\text { Standard } \\
\text { deviation }\end{array}$} \\
Number of dependents & 17.0000 & 80.0000 & 36.4193 & 12.0659 \\
l-Married, spouse present & 0.0000 & 6.0000 & 1.4288 & 1.4518 \\
l-White & 0.0000 & 1.0000 & 0.6972 & 0.4595 \\
Years of schooling & 0.0000 & 17.0000 & 11.6113 & 2.5457 \\
UI benefitb & 14.9100 & 160.0000 & 104.2192 & 27.9338 \\
Pre-UI income after taxes ${ }^{b}$ & 18.3300 & 443.4800 & 169.4875 & 66.5421 \\
UI replacement rate & 0.1930 & 0.9852 & 0.6600 & 0.1562 \\
Initial length of benefits $c$ & 8.0000 & 55.0000 & 34.2618 & 8.7977 \\
State unemployment rate & 4.7000 & 14.8100 & 8.6991 & 2.0812 \\
Weeks benefits received & 1.0000 & 39.0000 & 13.0487 & 10.3528 \\
\hline
\end{tabular}

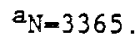

benefits and income are in 1977 dollars.

CInitial length of benefits is the number of weeks of benefits an individual is entitled to when his spell begins. 
Table 2

Failures, Censorings, and the Kaplan-Meier Eupirical Hazard ${ }^{a}$

\begin{tabular}{|c|c|c|c|c|c|}
\hline $\begin{array}{c}\text { Week } \\
t\end{array}$ & $\begin{array}{l}\text { Risk set } \\
R(t)\end{array}$ & $\begin{array}{l}\text { Fallures } \\
D(t)\end{array}$ & $\begin{array}{c}\text { Censorings } \\
C(t)\end{array}$ & $\begin{array}{l}\text { Hazard } \\
H(t)\end{array}$ & $\begin{array}{l}\text { Standard } \\
\text { error }\end{array}$ \\
\hline 1 & 3365 & 277 & 0 & .08232 & .0047 \\
\hline 2 & 3062 & 203 & 26 & .06630 & .0045 \\
\hline 3 & 2832 & 159 & 27 & .05614 & .0043 \\
\hline 4 & 2657 & 161 & 16 & .06059 & .0046 \\
\hline 5 & 2458 & 123 & 38 & .05004 & .0044 \\
\hline 6 & 2271 & 112 & 64 & .04932 & .0045 \\
\hline 7 & 2112 & 88 & 47 & .04167 & .0043 \\
\hline 8 & 1984 & 82 & 40 & .04133 & .0045 \\
\hline 9 & 1850 & 86 & 52 & .04649 & .0049 \\
\hline 10 & 1722 & 63 & 42 & .03659 & .0045 \\
\hline 11 & 1621. & 68 & 38 & .04195 & .0050 \\
\hline 12 & 1520 & 91 & 33 & .05987 & .0061 \\
\hline 13 & 1402 & 71 & 27 & .05064 & .0059 \\
\hline 14 & 1300 & 58 & 31 & .04462 & .0057 \\
\hline 15 & 1210 & 55 & 32 & .04545 & .0060 \\
\hline 16 & 1134 & 46 & 21 & .04056 & .0059 \\
\hline 17 & 1077 & 60 & 11 & .05571 & .0070 \\
\hline 18 & 999 & 58 & 18 & .05806 & .0074 \\
\hline 19 & 936 & 44 & 5 & .04701 & .0069 \\
\hline 20 & 880 & 41 & 12 & .04659 & .0071 \\
\hline 21 & 829 & 49 & 10 & .05911 & .0082 \\
\hline 22 & 773 & 45 & 7 & .05821 & 0084 \\
\hline 23 & 721 & 44 & 7 & .06103 & 0089 \\
\hline 24 & $662:$ & 34. & 15 & .05136 & .0086 \\
\hline 25 & 610 & 48 & 18 & .07869 & .0109 \\
\hline 26 & 430 & 45 & 132 & .10465 & .0148 \\
\hline 27 & 378 & 26 & 7 & .06878 & .0130 \\
\hline 28 & 317 & 30 & 35 & .09464 & .0164 \\
\hline 29 & 279 & 21 & 8 & .07527 & .0158 \\
\hline 30 & 245 & 13 & 13. & .05306 & .0143 \\
\hline 31 & 226 & 9 & 6 & .03982 & .0130 \\
\hline 32 & 212 & 17 & 5 & .08019 & .0187 \\
\hline 33 & 190 & 5 & 5 & .02632 & .0116 \\
\hline 34 & 178 & 8 & 7 & .04494 & .0155 \\
\hline 35 & 165 & 13 & 5 & .07879 & .0210 \\
\hline 36 & 121 & 12 & 31 & .09917 & .0272 \\
\hline 37 & 105 & 6 & 4 & .05714 & .0227 \\
\hline 38 & 91 & 9 & 8 & .09890 & .0313 \\
\hline
\end{tabular}

2380 fallures were observed, and 985 censorings. 201 of the censorings occurred at exhaustion of benefits. 
Table 3

Frequency Table for Initial and Kaximul Length of Benefits

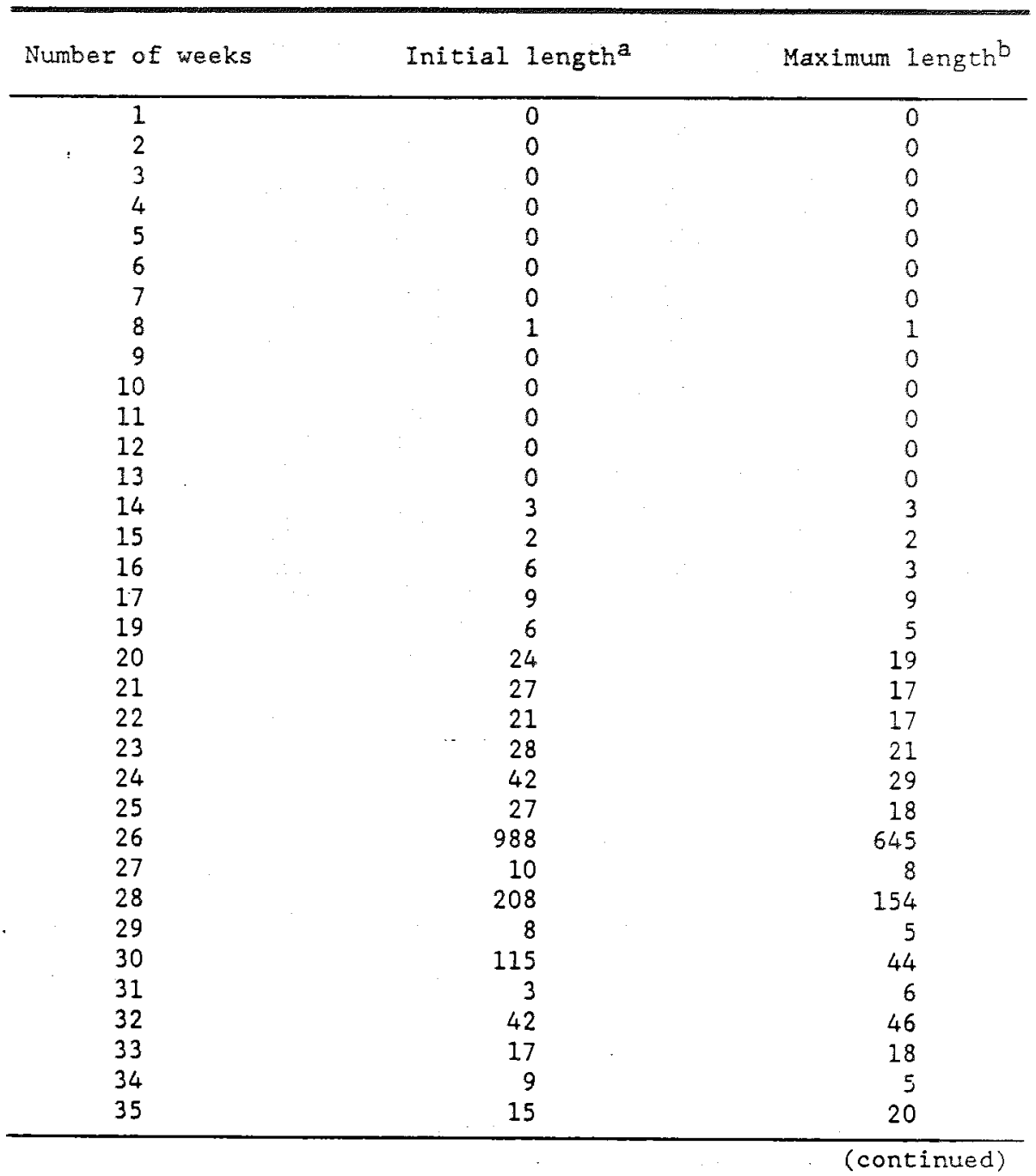


Table 3--Continued

\begin{tabular}{|c|c|c|c|}
\hline Number & of weeks & Initial lengtha & Maximum length \\
\hline & 36 & 230 & 258 \\
\hline & 37 & 2 & 1 \\
\hline & 38 & 49 & 36 \\
\hline & 39 & 890 & 919 \\
\hline & 40 & 145 & 138 \\
\hline & 41 & 2 & 1 \\
\hline & 42 & 12 & 3 \\
\hline & 43 & 4 & 7 \\
\hline & 44 & 22 & 7 \\
\hline & 45 & 3 & 1 \\
\hline & 46 & 4 & 6 \\
\hline & 47 & 3 & 9 \\
\hline & 48 & 3 & 15 \\
\hline$\because$ & 49 & 122 & 222 \\
\hline & 50 & 53 & 67 \\
\hline & 51 & 0 & 0 \\
\hline & 52 & 3 & 94 \\
\hline & 53 & 124 & 296 \\
\hline & 54 & 0 & 0 \\
\hline & 55 & 76 & 186 \\
\hline
\end{tabular}

Initial length is the number of weeks of benefits an individual is entitled to when his spell begins.

baximium length is the maximum number of weeks a person becomes entitled to in the course of his spel1. Maximum length exceeds initial length whenever benefits are extended. 
Table 4

Time Until Benefits Lapse Empirical Hazarda

\begin{tabular}{|c|c|c|c|c|c|}
\hline $\begin{array}{l}\text { Weeks } \\
\text { left }\end{array}$ & Risk set & Failures & Censorings & Hazard & $\begin{array}{l}\text { Seandard } \\
\text { error }\end{array}$ \\
\hline 1 & 303 & 50 & 1 & .165017 & .0213 \\
\hline 2 & 336 & 24 & 3 & .071429 & .0140 \\
\hline 3 & 390 & 38 & 1 & .097436 & .0150 \\
\hline 4 & 430 & 30 & 2 & .069767 & .0123 \\
\hline 5 & 466 & 31 & 1 & .066524 & .0115 \\
\hline 6 & 505 & 25 & 1 & .049505 & .0097 \\
\hline 7 & 543 & 28 & 1 & .051565 & .0095 \\
\hline 8 & 578 & 28 & 0 & .048443 & .0089 \\
\hline 9 & 617 & 28 & 5 & .045381 & .0084 \\
\hline 10 & 673 & 38 & 3 & .056464 & .0089 \\
\hline 11 & 755 & 52 & 5 & .068874 & .0092 \\
\hline 12 & 825 & 44 & 5 & .053333 & .0078 \\
\hline 13 & 909 & 54 & 16 & .059406 & .0078 \\
\hline 14 & 1011 & 59 & 5 & .058358 & .0074 \\
\hline 15 & 1084 & 49 & 6 & .045203 & .0063 \\
\hline 16 & 1132 & 40 & 6 & .035336 & .0055 \\
\hline 17 & 1217 & 63 & 7 & .051767 & .0064 \\
\hline 18 & 1300 & 59 & 3 & .045385 & .0058 \\
\hline 19 & 1367 & 68 & 8 & .049744 & .0059 \\
\hline 20 & 1435 & 72 & 7 & .050174 & .0058 \\
\hline 21 & 1496 & 69 & 6 & .046123 & .0054 \\
\hline 22 & 1577 & 91 & 9 & .057705 & .0059 \\
\hline 23 & 1654 & 82 & 14 & .049577 & .0053 \\
\hline 24 & 1774 & 121 & 15 & .068207 & .0060 \\
\hline 25 & 1954 & 138 & 13 & .070624 & .0058 \\
\hline 26 & 1030 & 52 & 22 & .050485 & .0068 \\
\hline 27 & 1101 & 66 & 24 & .059946 & .0072 \\
\hline 28 & 956 & 48 & 27 & .050209 & .0071 \\
\hline 29 & 1036 & 42 & 21 & .040541 & .0061 \\
\hline 30 & 986 & 50 & 27 & .050710 & .0070 \\
\hline 31 & 1040 & 55 & 22 & .052885 & .0069 \\
\hline 32 & 1071 & 67 & 14 & .062558 & .0074 \\
\hline 33 & 1124 & 58 & 21 & .051601 & .0066 \\
\hline 34 & 1210 & 74 & 20 & .061157 & .0069 \\
\hline 35 & 1281 & 66 & 19 & .051522 & .0062 \\
\hline 36 & 1110 & 71 & 6 & .063964 & .0073 \\
\hline 37 & 1193 & 78 & 23 & .065381 & .0072 \\
\hline 38 & 1231 & 85 & 21 & .069050 & .0072 \\
\hline 39 & 370 & 15 & 19 & .040541 & .0103 \\
\hline 40 & 253 & 11 & 19 & .043478 & .0128 \\
\hline
\end{tabular}


Table 4--Continued

\begin{tabular}{llcccc}
\hline $\begin{array}{l}\text { Weeks } \\
\text { left }\end{array}$ & Risk set & Failures & Censorings & Hazard & $\begin{array}{c}\text { Standard } \\
\text { error }\end{array}$ \\
\hline 41 & 268 & 11 & 14 & .041045 & .0121 \\
42 & 265 & 9 & 25 & .033962 & .0111 \\
43 & 303 & 18 & 20 & .059406 & .0136 \\
44 & 300 & 12 & 26 & .040000 & .0113 \\
45 & 312 & 13 & 24 & .041667 & .0113 \\
46 & 325 & 9 & 23 & .027692 & .0091 \\
47 & 355 & 21 & 30 & .059155 & .0125 \\
48 & 375 & 20 & 25 & .053333 & .0116 \\
49 & 275 & 15 & 23 & .054545 & .0137 \\
50 & 239 & 9 & 13 & .037657 & .0123 \\
51 & 228 & 11 & 12 & .048246 & .0142 \\
52 & 202 & 8 & 11 & .039604 & .0137 \\
53 & 78 & 2 & 8 & .025641 & .0179 \\
54 & 76 & 3 & 0 & .039474 & .0223 \\
\hline
\end{tabular}

aThis empirical hazard differs from the Kaplan-Meier hazard with the time axis reversed for two reasons. First, people begin with different lengths of benefits. Second, the time until benefits lapse does not always decrease by one each week, since the length of benefits often changes. Thus, the accounting identity given in footnote 8 will not hold and a person may appear more than once in the risk set for a given week. 
Table 5

Hazard Hodel Estimates ${ }^{a}$

\begin{tabular}{|c|c|c|c|c|c|}
\hline \multirow{2}{*}{ Variable } & \multicolumn{5}{|c|}{ Specification } \\
\hline & (1) & (2) & (3) & (4) & $(5)$ \\
\hline Number of dependents & $\begin{array}{l}-.0418 \\
(0.0169)\end{array}$ & $\begin{array}{l}-.0422 \\
(0.0171)\end{array}$ & $(0.0416)$ & $\begin{array}{c}-.0386 \\
(0.0239)\end{array}$ & $\begin{array}{l}-.0386 \\
(0.0242)\end{array}$ \\
\hline Immarried, spouse present & $(0.0508)$ & $(0.0515)$ & $(0.0507)$ & $\begin{array}{l}.1006 \\
(0.0722)\end{array}$ & $(0.0790)$ \\
\hline 1 =white & $\begin{array}{l}.2097 \\
(0.0572)\end{array}$ & $\begin{array}{l}.2230 \\
(0.0579)\end{array}$ & $(0.0568)$ & $(0.0834)$ & $\left\{\begin{array}{l}.2364 \\
(0.0841\}\end{array}\right.$ \\
\hline Years of schooling & $(0.0083)$ & $\begin{array}{c}-.0275 \\
(0.0084)\end{array}$ & $(0.0272)$ & $(0.0123)$ & $\begin{array}{l}-.0176 \\
(0.0124)\end{array}$ \\
\hline Log UI benefit leveI & $\begin{array}{l}-.8782 \\
(0.1091)\end{array}$ & $(0.1096)$ & $(0.1088)$ & $\begin{array}{l}=.8685 \\
(0.2042)\end{array}$ & $\begin{array}{l}-.8757 \\
(0.2065)\end{array}$ \\
\hline Log pre-UI after tax wage & $(0.0855)$ & $(0.0860)$ & $(0.0848)$ & $\begin{array}{l}.7289 \\
(0.1415)\end{array}$ & $\begin{array}{r}.7411 \\
(0.1433)\end{array}$ \\
\hline Age 17.24 & $(0.0855)$ & $\begin{array}{c}.2613 \\
(0.0865)\end{array}$ & $(0.0855)$ & $(0.1242)$ & $\begin{array}{r}.2670 \\
(0.1256)\end{array}$ \\
\hline Age $25-34$ & $(0.0750)$ & $\begin{array}{c}.1542 \\
(0.0759)\end{array}$ & $(0.0749)$ & $(0.1066)$ & $\begin{array}{c}.1068 \\
(0.1078)\end{array}$ \\
\hline Age $35-44$ & $\begin{array}{c}.1642 \\
(0.0776)\end{array}$ & $\begin{array}{c}.1594 \\
(0.0787)\end{array}$ & $(0.0774)$ & $\begin{array}{c}.1466 \\
(0.1110)\end{array}$ & $\begin{array}{c}.1492 \\
(0.1122)\end{array}$ \\
\hline Age $45-54$ & $\begin{array}{c}.0473 \\
(0.0828)\end{array}$ & $(0.0417)$ & $\begin{array}{c}.0460 \\
(0.0827)\end{array}$ & $(0.1156)$ & $(0.1169)$ \\
\hline $\begin{array}{l}\text { State unemployment rate } \\
\text { Exhaustion spline:b }\end{array}$ & $\begin{array}{c}-.0237 \\
(0.0133)\end{array}$ & $\begin{array}{c}.0019 \\
(0.0126)\end{array}$ & $\begin{array}{c}-.0234 \\
(0.0134)\end{array}$ & $(0.0967)$ & $\begin{array}{c}.0993 \\
(0.0218)\end{array}$ \\
\hline UI 1 & $\begin{array}{c}.6772 \\
(0.2470)\end{array}$ & $\begin{array}{c}.6473 \\
(0.1996)\end{array}$ & $\begin{array}{c}.5977 \\
(0.2479)\end{array}$ & $\begin{array}{c}.7379 \\
(0.2499)\end{array}$ & $(0.6670)$ \\
\hline UI $2-5$ & $(0.0612)$ & $\begin{array}{c}.1468 \\
(0.0519)\end{array}$ & $(0.0618)$ & $\begin{array}{c}.1448 \\
(0.0625)\end{array}$ & $(0.0634)$ \\
\hline
\end{tabular}


Table 5--Continued

\begin{tabular}{|c|c|c|c|c|c|}
\hline \multirow{2}{*}{ Variable } & \multicolumn{5}{|c|}{ Specification } \\
\hline & (1) & (2) & (3) & (4) & (5) \\
\hline UI $6-10$ & $(0.0317)$ & $(0.0280)$ & $(0.0317)$ & $\begin{array}{l}.0054 \\
(0.0334)\end{array}$ & $\begin{array}{c}.0052 \\
(0.0336)\end{array}$ \\
\hline UI $11-25$ & $\begin{array}{l}-.0052 \\
(0.0068)\end{array}$ & $(0.0074)$ & $\begin{array}{c}-.0067 \\
(0.0068)\end{array}$ & $\begin{array}{c}-.0093 \\
(0.0078)\end{array}$ & $\begin{array}{c}-.0102 \\
(0.0078)\end{array}$ \\
\hline UI $26-40$ & $\begin{array}{l}-.0018 \\
(0.0064)\end{array}$ & $(0.0016)$ & $\begin{array}{l}-.0008 \\
(0.0064)\end{array}$ & $\begin{array}{l}-.0001 \\
(0.0074)\end{array}$ & $(0.0075)$ \\
\hline UI $41-54$ & $(0.0133)$ & $(0.0133)$ & $\begin{array}{l}.0209 \\
(0.0134)\end{array}$ & $(0.0291$ & $(0.0289$ \\
\hline $\begin{array}{l}\text { Benefits previously } \\
\text { expected to lapse }\end{array}$ & & & $\begin{array}{l}1.4643 \\
(0.1876)\end{array}$ & & $\begin{array}{l}1.6280 \\
(0.2006)\end{array}$ \\
\hline State fixed effects & no & no & nó & yes & yes \\
\hline Nonparametric baseline & yes $^{d}$ & no & yes $^{e}$ & yes. & yes $^{f}$ \\
\hline Heterogeneity variance & $\mathrm{g}$ & $g$ & $g$ & $(0.7560)$ & $(0.7901)$ \\
\hline Sample size & 3365 & 3365 & 3365 & 3365 & 3365 \\
\hline Log-1ikelihood value & -9038.07 & -9085.06 & -9015.68 & -8927.80 & -8901.94 \\
\hline
\end{tabular}

astandard errors are shown in parentheses.

$b^{b}$ The exhaustion spline variables are defined in the text.

cIf earlier in the spell benefits were expected to lapse in the current week, the variable equals 1 , otherwise it equals 0 .

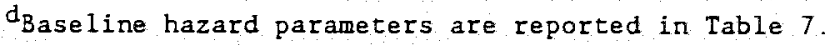

Easeline hazard parameters are reported in Table 8.

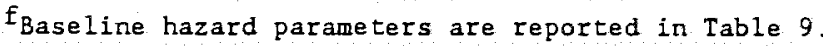

The unconstrained estimate of the variance is zero. 
Table 6

Additional hazard Model Estinates ${ }^{a}$

\begin{tabular}{|c|c|c|c|c|}
\hline \multirow{2}{*}{ Variable } & \multicolumn{4}{|c|}{ Specification } \\
\hline & (6) & (7) & (8) & (9) \\
\hline Number of dependents & $\begin{array}{c}-.0291 \\
(0.0172)\end{array}$ & $\begin{array}{c}-.0286 \\
(0.0171)\end{array}$ & $\begin{array}{c}-.0213 \\
(0.0286)\end{array}$ & $(0.0263)$ \\
\hline $1=$ married, spouse present & $\begin{array}{c}.0914 \\
(0.0510)\end{array}$ & $\begin{array}{c}.0972 \\
(0.0507)\end{array}$ & $(0.0861)$ & $\begin{array}{c}.0956 \\
(0.0699)\end{array}$ \\
\hline 1 white & $(0.0581)$ & $\begin{array}{c}. .1597 \\
(0.0578)\end{array}$ & $\begin{array}{c}.1339 \\
(0.1080)\end{array}$ & $\begin{array}{c}.1768 \\
(0.0801)\end{array}$ \\
\hline Years of schooling & $\begin{array}{c}-.0118 \\
(0.0085)\end{array}$ & $\begin{array}{l}-.0124 \\
(0.0085)\end{array}$ & $\begin{array}{l}-.0085 \\
(0.0150)\end{array}$ & $\begin{array}{c}-.0107 \\
(0.0129)\end{array}$ \\
\hline Log UI benefit level & $\begin{array}{c}-.6021 \\
(0.1390)\end{array}$ & $\begin{array}{c}-.5993 \\
(0.1386)\end{array}$ & $\begin{array}{c}-.5326 \\
(0.2420)\end{array}$ & $\begin{array}{c}-.5683 \\
(0.1848)\end{array}$ \\
\hline Log Pre-UI after tax wage & $(0.0938)$ & $\begin{array}{c}.4926 \\
(0.0943)\end{array}$ & $\begin{array}{c}.5327 \\
(0.1643)\end{array}$ & $\begin{array}{c}.2975 \\
(0.1391)\end{array}$ \\
\hline Age $17 \cdot 24$ & $\begin{array}{c}.2291 \\
(0.0863)\end{array}$ & $(0.0859)$ & $(0.1541)$ & $\begin{array}{c}.0350 \\
(0.1172)\end{array}$ \\
\hline Age $25-34$ & $\begin{array}{c}.1072 \\
(0.0758)\end{array}$ & $\begin{array}{c}.1110 \\
(0.0754)\end{array}$ & $\begin{array}{c}.1725 \\
(0.1331)\end{array}$ & $\begin{array}{c}-.0411 \\
(0.1031)\end{array}$ \\
\hline Age $35-44$ & $\begin{array}{c}.1001 \\
(0.0789)\end{array}$ & $\begin{array}{c}.1070 \\
(0.0787)\end{array}$ & $\begin{array}{c}.0180 \\
(0.1367)\end{array}$ & $\begin{array}{c}.0505 \\
(0.1049)\end{array}$ \\
\hline Age $45-54$ & $(0.0314$ & $(0.0323$ & $\begin{array}{c}.0354 \\
(0.1447)\end{array}$ & $\begin{array}{c}-.0674 \\
(0.1152)\end{array}$ \\
\hline State unemployment rate & $\begin{array}{c}.0794 \\
(0.0153)\end{array}$ & $\begin{array}{c}.0588 \\
(0.0166)\end{array}$ & $\begin{array}{c}.0389 \\
(0.0263)\end{array}$ & $\begin{array}{c}.3104 \\
(0.0363)\end{array}$ \\
\hline
\end{tabular}


Table 6--Continued

\begin{tabular}{|c|c|c|c|c|}
\hline \multirow{2}{*}{ Variable } & \multicolumn{4}{|c|}{ Specification } \\
\hline & (6) & (7) & (8) & (9) \\
\hline $\begin{array}{l}\text { Exhaustion spline: } \\
\text { UI } 1\end{array}$ & $(0.2002)$ & $(0.5772$ & $\begin{array}{c}.8942 \\
(0.4627)\end{array}$ & $(0.3182)$ \\
\hline UI $2-5$ & $(0.0521)$ & $\begin{array}{c}.1669 \\
(0.0621)\end{array}$ & $(0.1538$ & $\begin{array}{l}.0595 \\
(0.0746)\end{array}$ \\
\hline UI $6-10$ & $\begin{array}{c}.0183 \\
(0.0281)\end{array}$ & $(0.0320)$ & $(0.0124$ & $\begin{array}{c}-.0369 \\
(0.0404)\end{array}$ \\
\hline UI $11-25$ & $(0.0064)$ & $(0.0052$ & $(0.0120)$ & $\begin{array}{c}-.0682 \\
(0.0101)\end{array}$ \\
\hline UI $26-40$ & $(0.01065)$ & $\begin{array}{c}.0063 \\
(0.0068)\end{array}$ & $\begin{array}{l}-.0089 \\
(0.0099)\end{array}$ & $(0.0525)$ \\
\hline UI $41-54$ & $(0.0136)$ & $\begin{array}{l}.0213 \\
(0.0138)\end{array}$ & $\begin{array}{c}.0267 \\
(0.0164)\end{array}$ & d \\
\hline $\begin{array}{l}\text { Benefits previously } \\
\text { expected to lapse }\end{array}$ & $\begin{array}{l}1.7707 \\
(0.1558)\end{array}$ & $\begin{array}{c}1.5391 \\
(0.1881)\end{array}$ & $\begin{array}{c}1.2403 \\
(0.2902)\end{array}$ & $d$ \\
\hline Stace fixed effects & yes & yes & yes & yes \\
\hline Nonparametric baseline & no & yes & yes & yes \\
\hline Heterogeneity variance & e & & $\begin{array}{c}1829 \\
(0.1936)\end{array}$ & e \\
\hline Sample size & 3365 & 3365 & 1844 & 1521 \\
\hline Log-likelihood value & -8935.95 & -8906.79 & -3994.54 & -4729.65 \\
\hline
\end{tabular}

${ }^{a}$ Standard errors are shown in parentheses.

${ }^{b}$ The exhaustion spline variables are defined in the text.

cIf earlier in the spell benefits were expected to lapse in the current week, this variable equals 1 ; otherwise it equals 0 .

There is insufficient variation in the sample to estimate this coefficient.

eThe unconstrained estimate of the variance is zero. 
Table 7

Baseline Hazard Parameters from Specification (1)

\begin{tabular}{|c|c|c|c|c|c|}
\hline Week & Hazard & $\begin{array}{l}\text { Standard } \\
\text { error }\end{array}$ & $\begin{array}{l}\text { Nonline } \\
\text { confidence }\end{array}$ & $\begin{array}{l}\text { ar } 958 \\
\text { intervála }\end{array}$ & \\
\hline 1 & 0.08248 & 0.00507 & $(0.07311$ & .0 .09304 & ) \\
\hline 2 & 0.06642 & 0.00474 & $(0.05775$ & 0.07640 & ) \\
\hline 3 & 0.05628 & 0.00458 & $(0.04798$ & 0.06601 & ) \\
\hline 4 & 0.06115 & 0.00495 & $(0.05218$ & 0.07166 & $j$ \\
\hline 5 & 0.05046 & 0.00467 & $(0.04209$ & 0.06048 & $\xi$ \\
\hline 6 & 0.04987 & 0.00485 & $(0.04122$ & .0 .06034 & ) \\
\hline 7 & 0.04206 & 0.00459 & $(0.03396$ & 0.05209 & j \\
\hline 8 & 0,04184 & 0.00479 & $(0.03344$ & 0.05236 & j \\
\hline 9 & 0.04730 & 0.00532 & $(0.03795$ & 0.05896 & j \\
\hline 10 & 0.03717 & 0.00488 & $(0.02874$ & .0 .04809 & ; \\
\hline 11 & 0.04279 & 0.00546 & $(0.03332$ & 0.05496 & ) \\
\hline 12 & 0.06187 & 0.00700 & $(0.04956$ & $=0.07722$ & ) \\
\hline 13 & 0.05214 & 0.00663 & $(0.04064$ & 0.06689 & j \\
\hline 14 & 0.04592 & 0.00642 & $(0.03491$ & .0 .06039 & ) \\
\hline 15 & 0.04694 & 0.00680 & $(0.03534$ & 0.06236 & j \\
\hline 16 & 0.04168 & 0.00658 & $(0.03058$ & 0.05681 & ) \\
\hline 17 & 0.05753 & 0.00813 & $(0.04361$ & 0.07589 & j \\
\hline 18 & 0.06018 & 0.00870 & $(0.04533$ & 0.07991 & ) \\
\hline 19 & 0.04814 & 0.00795 & $(0.03482$ & 0.06655 & ) \\
\hline 20 & 0.04762 & 0.00824 & $(0.03393$ & 0.06684 & ) \\
\hline 21 & 0.05959 & 0.00964 & $(0.04340$ & 0.08181 & ) \\
\hline 22 & 0.05699 & 0.00936 & $(0.04130$ &, 0.07863 & ) \\
\hline 23 & 0.05713 & 0.00991 & $(0.04067$ & 0.08027 & ) \\
\hline 24 & 0.04624 & 0.00905 & $(0.03151$ & 0.06785 & ) \\
\hline 25 & 0.05513 & 0.01081 & $(0.03755$ & 0.08096 & $j$ \\
\hline 26 & 0.11264 & 0.01886 & $(0.08113$ & 0.15638 & j \\
\hline 27 & 0.06533 & 0.01446 & $(0.04233$ & .0 .10082 & j \\
\hline 28 & 0.10545 & 0.02129 & $(0.07099$ & 0.15664 & ) \\
\hline 29 & 0.08165 & 0.01926 & $(0.05143$ & 0.12964 & ) \\
\hline 30 & 0.05887 & 0.01701 & $(0.03341$ & 0.10373 & ) \\
\hline 31 & 0.04216 & 0.01472 & $(0.02126$ & 0.08359 & ) \\
\hline 32 & 0.08581 & 0.02276 & $(0.05103$ & 0.14432 & ) \\
\hline 33 & 0.02686 & 0.01249 & $(0.01080$ & 0.06683 & ) \\
\hline 34 & 0.04289 & 0.01584 & $(0.02079$ & 0.08845 & ) \\
\hline 35 & 0.05881 & 0.01766 & $(0.03265$ & 0.10594 & j \\
\hline 36 & 0.09162 & 0.02890 & $(0.04937$ & 0.17001 & ) \\
\hline 37 & 0.04583 & 0.02019 & $(0.01932$ & .0 .10869 & ) \\
\hline 38 & 0.04989 & 0.01859 & $(0.02404$ & 0.10355 & ) \\
\hline
\end{tabular}

aThe confidence incervals are calculated using a suggestion in Kalblfleisch and Prentice (1980). The hazard estimates and the standard errors are transformed to insure that the confidence intervals lie between 0 and 1 . The normal approximation used to calculate confidence intervals is more reasonable for the transformed hazard, especlally for values of the hazard close to 0 or 1 
Table 8

Baseline Hazard Paraneters from Specification (3)

\begin{tabular}{|c|c|c|c|c|c|}
\hline Week & Hazard & $\begin{array}{l}\text { Standard } \\
\text { error }\end{array}$ & $\begin{array}{l}\text { Nonline } \\
\text { confidence }\end{array}$ & $\begin{array}{l}\text { ar } 958 \\
\text { Interval }\end{array}$ & \\
\hline 1 & 0.08259 & 0.00508 & $(0.07321$ & 0.09317 & $y$ \\
\hline 2 & 0.06653 & 0.00475 & $(0.05784$ & 0.07652 & ) \\
\hline 3 & 0.05638 & 0.00459 & $(0.04807$ & 0.06613 & ) \\
\hline 4 & 0.06128 & 0.00496 & $(0.05229$ & 0.07181 & ) \\
\hline 5 & 0.05057 & 0.00468 & $(0.04219$ & 0.06062 & ) \\
\hline 6 & 0.04999 & 0.00486 & $(0.04132$ & 0.06048 & $y$ \\
\hline 7 & 0.04217 & 0.00460 & $(0.03404$ & 0.05222 & ) \\
\hline 8 & 0.04196 & 0.00480 & $(0.03353$ & 0.05251 & ) \\
\hline 9 & 0.04743 & 0.00533 & $(0.03805$ & 0.05913 & ) \\
\hline 10 & 0.03729 & 0.00490 & $(0.02882$ & 0.04824 & ) \\
\hline 11 & 0.04294 & 0.00548 & $(0.03344$ & 0.05514 & ) \\
\hline 12 & 0.06208 & 0.00702 & $(0.04974$ & 0.07749 & ) \\
\hline 13 & 0.05233 & 0.00665 & $(0.04079$ & 0.06713 & ) \\
\hline 14 & 0.04612 & 0.00645 & $(0.03507$ & 0.06066 & ) \\
\hline 15 & 0.04717 & 0.00683 & $(0.03551$ & 0.06266 & ) \\
\hline 16 & 0.04176 & 0.00661 & $(0.03063$ & 0.05695 & ) \\
\hline 17 & 0.05794 & 0.00819 & $(0.04391$. & 0.07644 & ) \\
\hline 18 & 0.06070 & 0.00878 & $(0.04571$ & .0 .08060 & ) \\
\hline 19 & 0.04831 & 0.00799 & $(0.03494$ & 0.06679 & ) \\
\hline 20 & 0.04783 & 0.00827 & $(0.03408$ & 0.06714 & ) \\
\hline 21 & 0.05953 & 0.00963 & $(0.04335$ & 0.08174 & ) \\
\hline 22 & 0.05612 & 0.00924 & $(0.04063$ & 0.07750 & ) \\
\hline 23 & 0.05551 & 0.00967 & $(0.03945$ & 0.07810 & ) \\
\hline 24 & 0.04423 & 0.00870 & $(0.03008$ & 0.06503 & ) \\
\hline 25 & 0.05368 & 0.01062 & $(0.03642$ & 0.07911 & ) \\
\hline 26 & 0.06529 & 0.01271 & $(0.04459$ & 0.09562 & ) \\
\hline 27 & 0.06467 & 0.01444 & $(0.04175$ & 0.10019 & ) \\
\hline 28 & 0.09327 & 0.01984 & $(0.06147$ & 0.14152 & ) \\
\hline 29 & 0.08227 & 0.01941 & 0.05180 & 0.13064 & ) \\
\hline 30 & 0.04872 & 0.01393 & 0.02782 & 0.08532 & ) \\
\hline 31 & 0.04253 & 0.01487 & $(0.02144$ & 0.08439 & ) \\
\hline 32 & 0.08080 & 0.02148 & $(0.04799$ & 0.13604 & ) \\
\hline 33 & 0.02643 & 0.01229 & $(0.01062$ & 0.06574 & ) \\
\hline 34 & 0.04132 & 0.01546 & $(0.01984$ & 0.08604 & ) \\
\hline 35 & 0.05722 & 0.01720 & $(0.03175$ & 0.10312 & ) \\
\hline 36 & 0.05472 & 0.01694 & $(0.02982$ & 0.10040 & ) \\
\hline 37 & 0.04225 & 0.01867 & $(0.01777$ & 0.10046 & ) \\
\hline 38 & 0.04538 & 0.01739 & $(0.02142$ & $\because 0.09616$ & ) \\
\hline
\end{tabular}

aThe confidence intervals are calculated using a suggestion In Kalblflelsch and Prentice (1980).. The hazard estimates and the standard errors are transformed to Insure that the confidence intervals $11 \mathrm{e}$ between 0 and 1 . The normal approximation used to calculate confidence intervals is more reasonable for the transformed hazard, especlally for values of the hazard close to 0 or 1 . 
Table 9

Baseline Hazard Parameters from Specification (5)

\begin{tabular}{|c|c|c|c|c|}
\hline Week & Hazard & $\begin{array}{l}\text { Standard } \\
\text { error }\end{array}$ & $\begin{array}{r}\text { Nonline } \\
\text { confidence }\end{array}$ & $\begin{array}{l}\text { 8r } 958 \\
\text { interva }{ }^{a}\end{array}$ \\
\hline 1 & 0.07678 & 0.00506 & $(0.06747$ & 0.08737 \\
\hline 2 & 0.06733 & 0.00510 & $(0.05804$ & 0.07811 \\
\hline 3 & 0.06086 & 0.00547 & $(0.05104$ & 0.07257 \\
\hline 4 & 0.07039 & 0.00675 & $(0.05833$ & 0.08493 \\
\hline 5 & 0.06174 & 0.00699 & $(0.04945$ & 0.07708 \\
\hline 6 & 0.06484 & 0.00811 & $(0.05075$ & 0.08285 \\
\hline 7 & 0.05756 & 0.00800 & $(0.04384$ & 0.07558 \\
\hline 8 & 0.05972 & 0.00888 & $(0.04462$ & 0.07992 \\
\hline 9 & 0.07002 & 0.01055 & $(0.05212$ & 0.09408 \\
\hline 10 & 0.05676 & 0.00976 & $(0.04052$ & 0.07950 \\
\hline 11 & 0.06740 & 0.01182 & $(0.04780$ & 0.09504 \\
\hline 12 & 0.10158 & 0.01764 & $(0.07227$ & 0.14278 \\
\hline 13 & 0.08977 & 0.01720 & $(0.06166$ & 0.13068 \\
\hline 14 & 0.08221 & 0.01673 & $(0.05517$ & 0.12250 \\
\hline 15 & 0.08728 & 0.01902 & $(0.05695$ & 0.13377 \\
\hline 16 & 0.07952 & 0.01821 & $(0.05077$ & 0.12456 \\
\hline 17 & 0.11423 & 0.02604 & $(0.07307$ & 0.17858 \\
\hline 18 & 0.12548 & 0.03013 & $(0.07838$ & 0.20088 \\
\hline 19 & 0.10432 & 0.02734 & $(0.06242$ & 0.17436 \\
\hline 20 & 0.10653 & 0.02949 & $(0.06192$ & 0.18329 \\
\hline 21 & 0.13753 & 0.03766 & $(0.08042$ & 0.23522 \\
\hline 22 & 0.13529 & 0.03839 & $(0.07758$ & 0.23593 \\
\hline 23 & 0.13898 & 0.04144 & $(0.07747$ & 0.24932 \\
\hline 24 & 0.11567 & 0.03674 & $(0.06206$ & 0.21557 \\
\hline 25 & 0.14613 & 0.04820 & $(0.07656$ & 0.27892 \\
\hline 26 & 0.18764 & 0.06260 & $(0.09757$ & 0.36084 \\
\hline 27 & 0.19283 & 0.06945 & $(0.09519$ & 0.39063 \\
\hline 28 & 0.28961 & 0.10902 & $(0.13848$ & 0.60566 \\
\hline 29 & 0.28126 & 0.11213 & $(0.12876$ & 0.61441 \\
\hline 30 & 0.17664 & 0.07732 & $(0.07490$ & 0.41657 \\
\hline 31 & 0.15690 & 0.07764 & $(0.05949$ & 0.41382 \\
\hline 32 & 0.31372 & 0.13892 & $(0.13171$ & 0.74726 \\
\hline 33 & 0.10833 & 0.06347 & $(0.03436$ & 0.34156 \\
\hline 34 & 0.16971 & 0.09050 & $(0.05968$ & 0.48263 \\
\hline 35 & 0.24550 & 0.11848 & $(0.09533$ & 0.63220 \\
\hline 36 & 0.24293 & 0.12045 & 0.09193 & 0.64198 \\
\hline 37 & 0.18918 & 0.11646 & 0.05661 & 0.63224 \\
\hline 38 & 0.20221 & 0.11487 & $(0.06641$ & 0.61571 \\
\hline
\end{tabular}

'The confidence intervals are calculated using a suggestion in Kalblfleisch and Prentice (1980). The hazard estimates and the standard errors are transformed to insure that the confidence intervals lie between 0 and 1 . The normal approximation used to calculate confidence intervals is more reasonable for the transformed hazard, especially for values of the hazard close to 0 or 1 . 
Figure 1

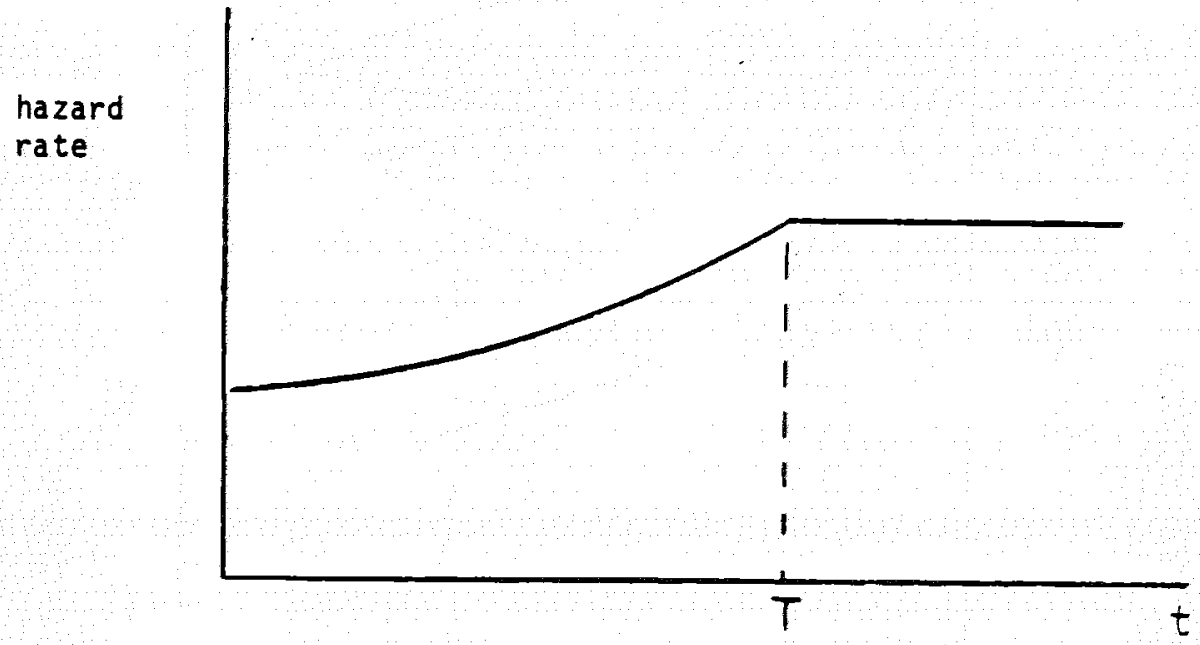

Figure 2

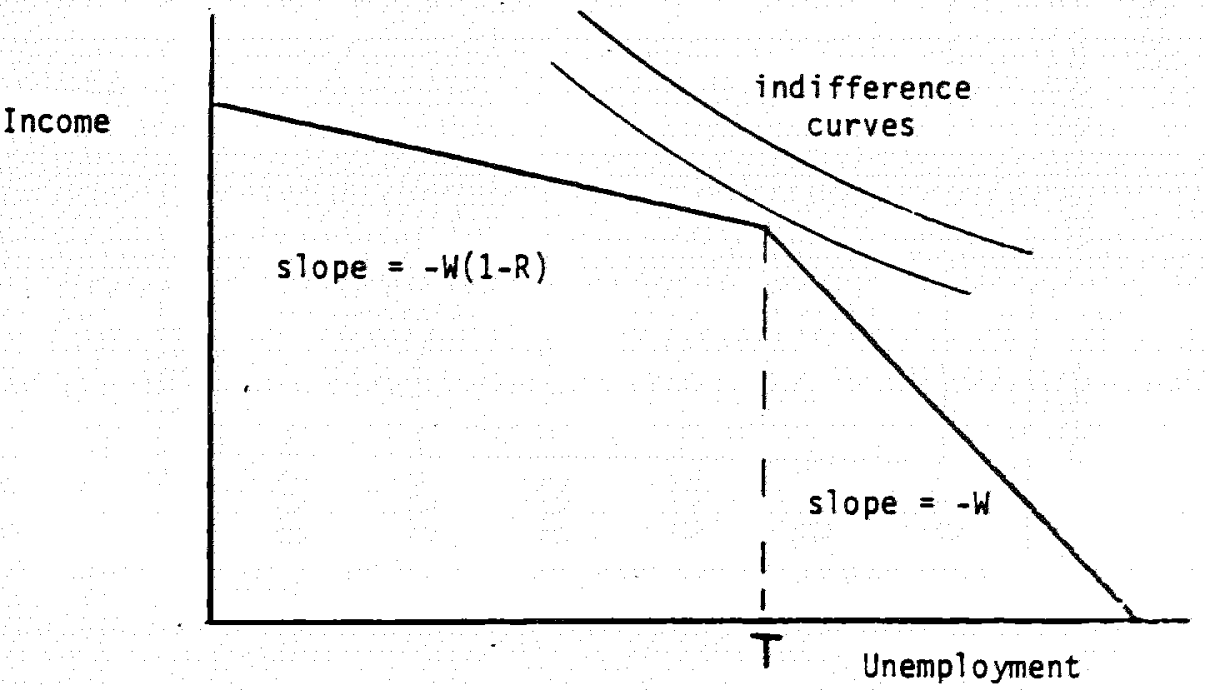




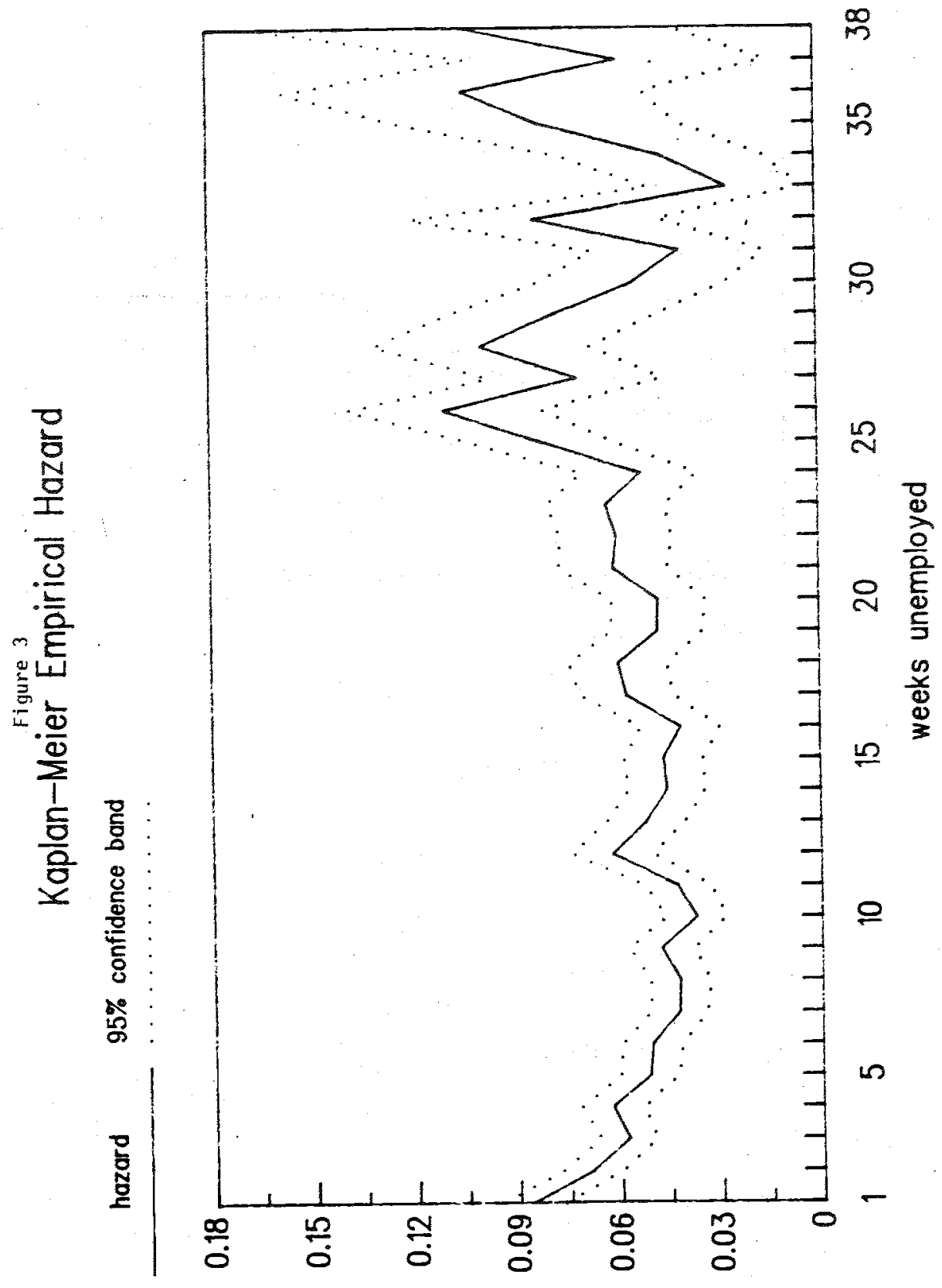




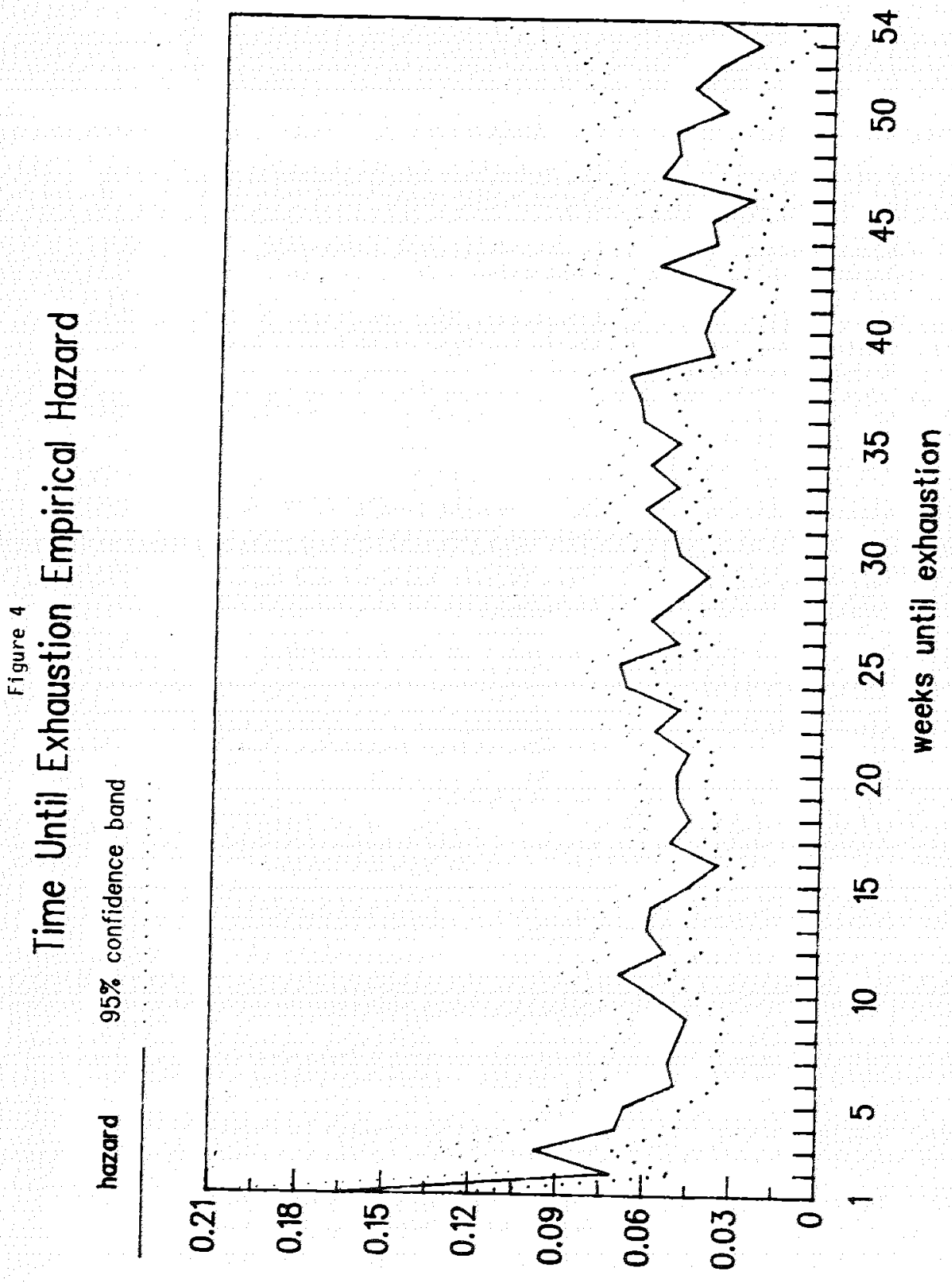

